Yüzüncü Y1l Üniversitesi
Tarim Bilimleri Dergisi

Araştırma Makalesi (Research Article)

\title{
Kısıtlı Sulama Uygulamalarının İHA Multispektral Algılamaya Dayalı Vejetasyon İndekslerine Etkisi
}

\author{
Sinan DEMIR ${ }^{1}$, Levent BAŞAYIĞ́̆iT ${ }^{2}$ \\ 1,2 Isparta Uygulamalı Bilimler Üniversitesi, Ziraat Fakültesi, Toprak Bilimi ve Bitki Besleme Bölümü, Isparta \\ ${ }^{1}$ https://orcid.org/0000-0002-1119-1186 ${ }^{2}$ https://orcid.org/0000-0003-2431-5763 \\ *Sorumlu yazar e-posta:demirsinan.07@gmail.com.tr
}

\section{Makale Bilgileri}

Geliș: 07.04.2021

Kabul: 31.05.2021

Online Yayınlanma: 30.09.202

DOI: $10.29133 /$ yyutbd.910909

\section{Anahtar Kelimeler}

Silajlik Misır,

Su kisit1,

Sulama yöntemi,

Multispektral sensör,

Vejetasyon indeksi,

İnsansız Hava Araçları (İHA)
Öz: Tarımsal yetiştiricilikte artan su talepleri, günümüz gelişen ve teknolojilerini daha iyi sulama yönetimi stratejilerini geliştirmeyi zorunlu hale getirmiştir. Görüntüleme teknolojilerine dayalı bilgi üretimi de bu amaçlı kullanımlar içerisinde yer almaktadır. Bu çalışmada, İHA tabanlı multispektral görüntülerin yüzey altı ve yüzey üstü damla sulama uygulamalarının değerlendirilmesinde kullanılabilirliği araştırılmıştır. Bu amaçla ET0 $(0.00,0.25,0.50,0.75,1.00,1.25$, 1.5) katları olacak şekilde programlanan bir slajlık mısır denemesinin büyüme sezonu boyunca insansız hava aracı kullanılarak görüntülenmiştir. Alınan görüntülerde 9 farklı vejetasyon indeksi oluşturularak uygulamaların izlenmesinde kullanılabilirlikleri birbirleri ile karşılaştırılmıştır. Yüzey altı damlama sulama yönteminde LCI ve TGI indeksleri, yüzey üstü damlama sulama yönteminde VARI indeksinin sulama programları düzeyinde kullanılabileceği belirlenmiştir $(\mathrm{p}<0.05)$. Gelişme dönemi boyunca temporal veriler incelendiğinde 9 bitki indeksi sonuçları arasında farklılıklar olduğu tespit edilmiştir $(p<0.05)$. Multispektral görüntülerin analizinden türetilen yüzey ve yüzey altı damla sulama yöntemleri Vejetasyon İndeksleri (VI) ile karşılaştıııldığında işlemler arasında istatistiksel olarak anlamlı farklılık olduğu gözlemlenmiştir. Sulama oranları karşılaştırıldığında, bitki örtüsü indeksi değerlerinde de benzer farklılıklar belirlenmiştir. Elde edilen sonuçlar, farklı sulama uygulamalarına bitkilerin tepkilerini karakterize etmek için İHA entegrasyonlu multispektral görüntülerin uygulanabilirliğini göstermiştir. İHA'lar ile yapılan Akıllı Tarım, Hassas Tarım, Organik Tarım ve İyi Tarım Uygulamalarının çiftlik düzeyinde yüksek kullanım potansiyeline sahip olacağı düşünülmektedir.

\section{The Effect of Restricted Irrigation Applications on Vegetation Index Based on UAV Multispectral Sensing}

\section{Article Info}

Received: 07.04.2021

Accepted: 31.05.2021

Online Published: 30.09.2021

DOI: 10.29133/yyutbd.910909

Keywords

Silage Corn,

Water limited,
Abstract: Increasing water demands in agricultural cultivation have made it necessary to develop better irrigation management strategies within today's development and technologies. Information production based on imaging technologies is also included in these uses. In this study, the usability of UAVbased multispectral images in the evaluation of subsurface and surface drip irrigation applications was investigated. For this purpose, a silage maize trial programmed to be multiples of ET0 $(0.00,0.25,0.50,0.75,1.00,1.25,1.5)$ was imaged using an unmanned aerial vehicle during the growing season. 9 different vegetation indexes were created in the images taken and their usability in monitoring the applications was compared with each other. It was determined that LCI and TGI indexes in subsurface drip irrigation method and VARI index in 
Irrigation method, Multispectral sensor, Vegetation index, Unmanned Aerial Vehicles (UAV). surface drip irrigation method can be used at the level of irrigation programs $(p<0.05)$. When the temporal data were examined during the development period, it was determined that there were differences between the 9 plant index results $(p<0.05)$. When the surface and subsurface drip irrigation methods derived from the analysis of multispectral images were compared with the Vegetation Indexes (VI), it was observed that there was a statistically significant difference between the treatments. When irrigation rates were compared, similar differences were determined in vegetation index values. The obtained results demonstrated the feasibility of UAV-integrated multispectral images to characterize the responses of plants to different irrigation applications. It is thought that Smart Agriculture, Precision Agriculture, Organic Agriculture, and Good Agricultural Practices made with UAVs will have high utilization potential at the farm level.

\section{Giriş}

Tüm iklim bölgelerini tehdit eden kuraklık, araştırmacıların ve yöneticilerin acil eylem planları ve uygulamaları açısında dikkatini çekmektedir. Mevcut iklim değişikliği tahminleri yakın gelecekte Akdeniz ve yarı kurak bölgelerde kurak dönemlerin sıklığında ve şiddetindeki artışlara işaret etmektedir. Ayrıca 2050 yılı için öngörülen küresel gıda talebi, tarımsal üretimin ve buna bağlı su kullanımının katlanarak artması gerektiğini göstermektedir (Danandeh Mehr ve ark., 2020). Dünyadaki tatlı su kaynaklarının çoğu (\% 70) tarım için kullanılmaktadır. Aynı zamanda, diğer sektörlerde de artan su tüketimi, gıda üretimi için kullanılan su için bir rekabet oluşturmaktadır. Su talebindeki artış ve iklim değişikliği bu olumsuzlukların kuraklık üzerine etkilerini arttırmaktadır (Tiryaki, 2018). Küresel olarak dünyadaki gıda arzının \% 45'i, ekilebilir alanların yalnızca \% 18'ini kapsayan sulanan arazilerde üretilmektedir. Bu durum, sulama yönetiminde su kullanımını optimize etmenin önemli olduğu anlamına gelmektedir. Su kaynağı kıtlığ su yönetiminin en önemli sorunlarından biridir (Fernández García ve ark., 2020). Su kullanım etkinliğini artırmanın önemli yollarından biri de çeşitli bitkiler için üzerinde uzun yıllardır araştırma yapılan kısıtlı sulama uygulamasıdır. Bununla birlikte, verim ve sulama suyu arasında hassas bir denge sağlamak için etkili izleme yöntemleri gerekmektedir. Bu nedenle, çevreyle ilişkili olarak bitki örtüsündeki dinamik değişiklikleri dikkate almak önemlidir (Demir ve Başayiğit, 2020).

Toprak nem içeriğinde gerçekleşen azalmaya bağlı olarak bitkilerin içsel su durumunu gösteren stoma iletkenliği ve yaprak su potansiyeli gibi çeşitli fizyolojik özellikler uzaktan algilama teknolojileri kullanılarak tespit edilebilmektedir (Uçar, 2011). Toprak su içeriğine bağlı olarak bitkilerin bazı fizyolojik özelliklerinde gerçekleşen değişimlerin yerinde ölçümleri zaman alıcı, zahmetli ve maliyetli olmaktadır. $\mathrm{Bu}$ yöntemlerde, toprak ile bitki arasındaki mekansal değişkenlik ilişkisi yeterince değerlendirilememekte iken, günümüzde çeşitli uzaktan algılama platformlarından çok sayıda veri elde edilebilmekte ve bitki su stresini izleme çalışmalarında kullanılmaktadır. Uzaktan algılamanın tarımsal amaçlı olarak en yaygın kullanımı uydu platformlarından temin edilen farklı özelliklerdeki görüntülerdir. Ancak uydu platformları, uzamsal-zamansal çözünürlüğe bağlı artan maliyetleri, kısıtlı gerçek zamanlı görüntüleme kabiliyetleri ve atmosfer koşullarından etkilenme gibi çeşitli dezavantajlara sahiptir. Bu nedenle günümüzde İHA'lar (insansız hava araçları) yeni nesil uzaktan algılama araçları olarak devreye girmekte ve daha esnek çalışma kabiliyetleri sunmaktadır. Sensörlerle donatılmış hava platformları kullanılarak uygun maliyetlerle bazı çalışmalar da kullanılabileceği belirtilmiştir. Ancak, bu ekipmanların izleme alanlarına taşınması ve şerit haritalama kabiliyetini azaltmasından dolayı kullanımları kısıtlanmaktadır (Calera ve ark., 2017; Demir ve Başayiğit, 2020).

Son yıllarda teknolojik gelişmeler ile birlikte İHA'ların sivil amaçlı kullanımı artmaya başlamıştır. Düşük maliyet, yapımı kolay, rahat ulaşım, yüksek esneklikte çalışma olanağı sunması, kısa çalışma döngüsü ve yüksek uzaysal-zamansal çözünürlük avantajları nedeniyle, insansız hava aracı (İHA) uzaktan algılama sistemi olarak kullanımı artmaktadır. Mahsul bilgilerini istenen bir uzaysalzamansal çözünürlükte İHA ile toplanabilmektedir (Demir ve Başayiğit, 2020). Belirtilen özellikler İHA'ların bitki su stresini çiftlik ölçeğinde hızlı ve titizlikle izlemeyi daha uygun hale getirmiştir.

Bitki örtüsünün ve karşılık gelen banttaki diğer yer nesnelerinin yansıtımının matematiksel işlem sonucu olan bitki örtüsü indeksi (VI), yüzey bitki örtüsü durumunu izlemek için kullanılabilmektedir. Bitki indeksi; arazi örtüsü sınıflandırması, çevresel değişiklikler ve kuraklığı 
izlemek amaciyla başarıyla uygulanmaktadır (Xue ve Su ,2017; Han ve ark., 2018; Wahab ve ark., 2018; Kumar ve ark., 2020; Becker ve ark., 2020; Zhang ve ark., 2021). Suyun yeni bir değer olarak yükseldiği günümüzde teknolojiye dayalı bu araştırmaların önemi daha da artmaktadır.

$\mathrm{Bu}$ çalışmada; yüzey altı ve yüzey üstü damlama sulama yöntemi ile farklı düzeylerde sulama suyu uygulanan silajlık mısırın; (1) yüksek çözünürlüklü İHA tabanlı multispektral ve temporal görüntülerinin alınması, (2) vejetasyon indekslerinin üretilmesi, (3) su seviyelerindeki vejetasyon indekslerinin parsel bazlı ve dönemsel olarak yansıma verilerine dayalı sulama programlarının istatistiksel olarak belirlenmesi çalışması yer almaktadır.

\section{Materyal ve Yöntem}

\section{1. Çalışma Alanının Konumu ve İklimi}

Çalışma alanı, Isparta-Burdur Karayolunun doğusunda, üniversite yerleşim birimleri ile Isparta Mensucat fabrikası arasında, Göller Bölgesi Teknokent ile ISUBU Ziraat Fakültesi arasında kalan Eğitim, Araştırma ve Uygulama Çiftliği araştırma parseli içerisinde 4190803.07-41900845.45 N kuzey enlemleri - 283075.62-283208.54E doğu boylamları (WGS-1984, UTM-m, 36N Zon) arasında yer almaktadır. Toplam 7862 metrekare alana sahiptir (Şekil 1). Meteoroloji Genel Müdürlüğü 17240 numaralı Isparta Merkez istasyonu 2018 y1l iklim verilerine göre; y1llık ortalama sıcaklık $13.8{ }^{\circ} \mathrm{C}$, en düşük aylık ortalama sıcaklık $3.1{ }^{\circ} \mathrm{C}$ Ocak ayında, en yüksek aylık ortalama sıcaklık $24.3{ }^{\circ} \mathrm{C}$ ' ile Temmuz ve Ağustos aylarında tespit edilmiştir. Yıllık ortalama yağış $536.9 \mathrm{~mm}$, en yüksek yağış 107.1 mm Aralık ayında, en düşük yağış $1.6 \mathrm{~mm}$ ile Eylül ayında tespit edilmiştir (MGM, 2021). McKee ve ark. (1993)'e göre Standart Yağış İndeksi (SPI) hesaplanmıştır (Danandeh Mehr ve ark., 2020). Çalışma alanının SPI değerleri 1990-2019 yılları arasındaki iklim verileri kullanılarak hesaplanmıştır. 2018 yılına ait SPI değerleri, yıllık, aylık ve kuraklık kategorisi Temmuz, Ağustos ve Eylül ayları ve 2018 yıllı "Normale Yakın Kuraklık " kuraklık kategorisi içerisinde yer almıştır.

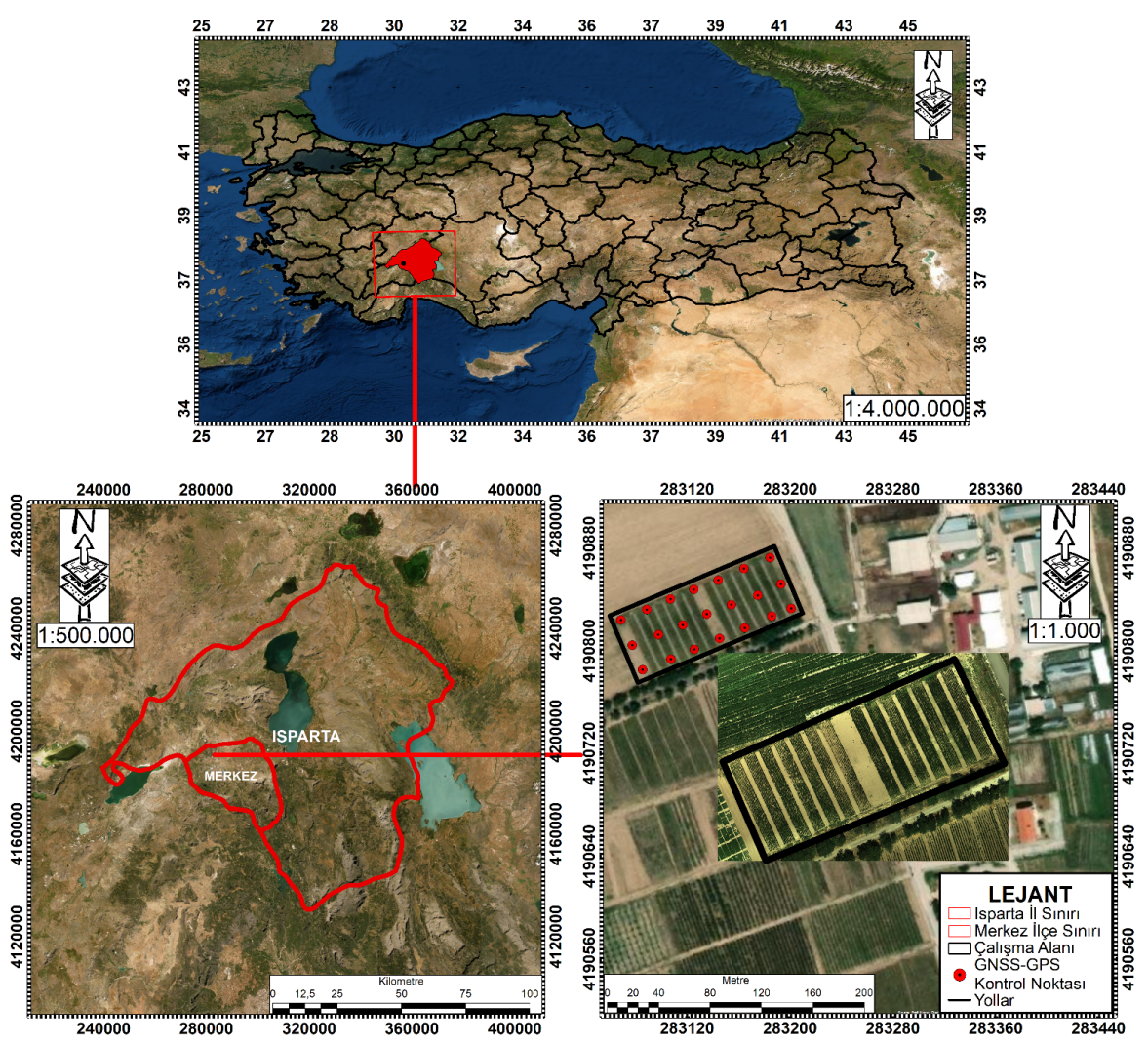

Şekil 1. Çalışma alanının konum haritası. 


\subsection{Deneme Konuları}

Çalışma alanı ve çevresinde silajlık mısır yetiştiriciliği yapılan dönemlerde SPI değerleri normale yakın kuraklık kategorisinde yer almıştır. Bu nedenle mısırın vejetasyon döneminde ihtiyaç duyduğu suyun uygun yöntem ve uygun programda verilmesi bölgede su kullanımı yönünden önem arz etmektedir (Çakmakçı ve ark., 2017; Alaboz ve ark., 2020; Çakmakçı ve Şahin, 2020; Alaboz ve Çakmakçı, 2020). Çalışmada, su tasarrufu yönünden etkin olan yüzey üstü ve yüzey altı damla sulama yöntemleri ile referans bitki su tüketimi (ET0)'ya göre 7 farklı sulama programı olacak şekilde deneme kurulmuştur (Şekil 2).

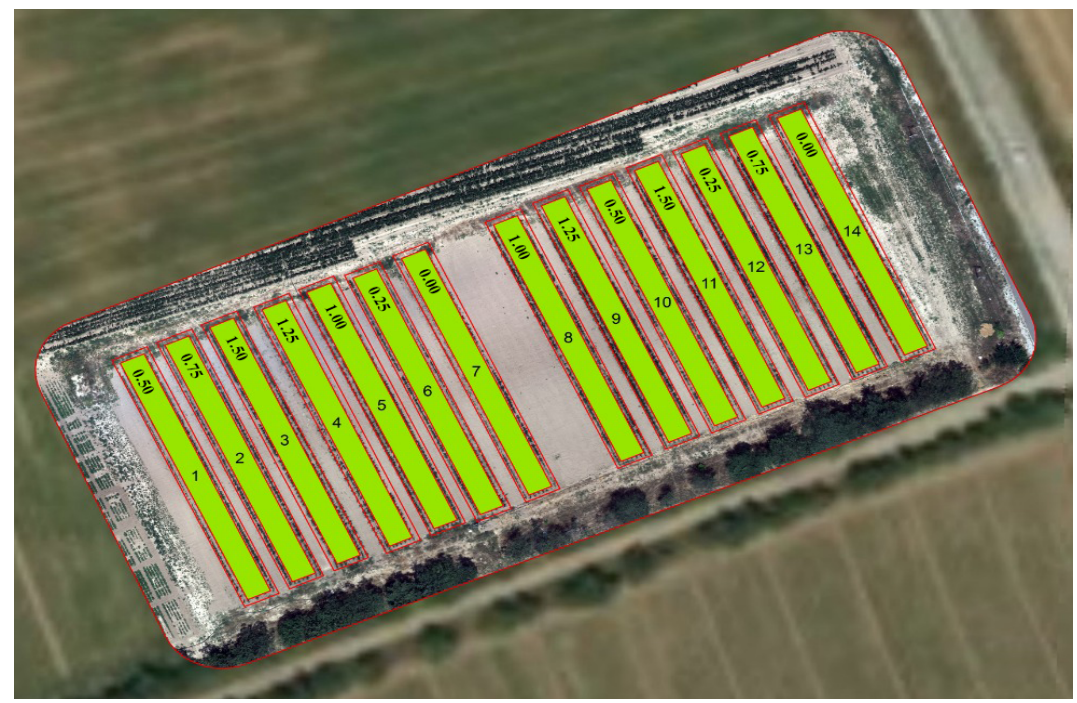

Şekil 2. Deneme planı.

ET0 baz alınarak oluşturulan 7 farklı sulama programı Parsel 1, 2, 3, 4, 5, 6 ve 7 için yüzey altı damla sulama yöntemi ve Parsel 8, 9, 10,11,12,13 ve 14 için yüzey üstü damla sulama yöntemi olarak planlanmıştır. Parsellere ait deneme konuları Şekil 2'de gösterilmiştir.

ET0, Penman Monteith yöntemine göre hesaplanmıştır (Uçar ve ark., 2017). Deneme konularına ET0'ın (Referans bitki su tüketimi) $0.00,0.25,0.50,0.75,1.00,1.25$ ve 1.50 kat1 sulama suyu uygulanmıştır (Tablo 1). 22.06.2018 tarihinde bütün konuları tarla kapasitesine getirilecek kadar sulama suyu uygulanmıştır. 0 konusuna 22.06.2018 tarihinden sonra sulama suyu uygulanmamıştır.

Tablo 1. Denemede konularına uygulanan sulama suyu miktarı (mm)

\begin{tabular}{|c|c|c|c|c|c|c|c|}
\hline Sulama Tarihleri & $\begin{array}{c}\text { S1 } \\
1.50\end{array}$ & $\begin{array}{c}\text { S2 } \\
1.25\end{array}$ & $\begin{array}{c}\text { S3 } \\
1.00\end{array}$ & $\begin{array}{c}\text { S4 } \\
0.75\end{array}$ & $\begin{array}{c}\text { S5 } \\
0.50\end{array}$ & $\begin{array}{c}\text { S6 } \\
0.25 \\
\end{array}$ & $\begin{array}{c}\text { S7 } \\
0.00\end{array}$ \\
\hline 09.06 .2018 & 20.2 & 20.2 & 20.2 & 20.2 & 20.2 & 20.2 & 20.2 \\
\hline 15.06 .2018 & 30.7 & 30.7 & 30.7 & 30.7 & 30.7 & 30.7 & 30.7 \\
\hline 22.06 .2018 & 40.8 & 40.8 & 40.8 & 40.8 & 40.8 & 40.8 & 40.8 \\
\hline 29.06 .2018 & 54.8 & 45.6 & 36.5 & 27.4 & 18.3 & 9.1 & \\
\hline 06.07.2018 & 53.7 & 44.8 & 35.8 & 26.9 & 17.9 & 9.0 & \\
\hline 13.07 .2018 & 61.1 & 50.9 & 40.7 & 30.5 & 20.4 & 10.2 & \\
\hline 20.07.2018 & 55.8 & 46.5 & 37.2 & 27.9 & 18.6 & 9.3 & \\
\hline 27.07 .2018 & 55.8 & 46.5 & 37.2 & 27.9 & 18.6 & 9.3 & \\
\hline 03.08 .2018 & 52.4 & 43.6 & 34.9 & 26.2 & 17.5 & 8.7 & \\
\hline 10.08 .2018 & 45.8 & 38.1 & 30.5 & 22.9 & 15.3 & 7.6 & \\
\hline 17.08.2018 & 48.5 & 40.4 & 32.3 & 24.2 & 16.2 & 8.1 & \\
\hline TOPLAM & 519.4 & 448.1 & 376.8 & 305.5 & 234.3 & 163.0 & 91.7 \\
\hline
\end{tabular}

\subsection{Kültürel Uygulamalar}

Denemelerin kurulacağı parsel önce pullukla sürüm yapılmış ve ardından rotatiller ile sürülerek dikime hazır duruma getirilmiştir. Toprak analiz sonuçları dikkate alınarak, ekimle birlikte damla 
sulama sisteminde yer alan venturi gübreleme sistemiyle ilk gübreleme (10 $\mathrm{kg} \mathrm{da}^{-1}$ AquaDrip 20-20-20TE) yapılmıştır. 1 Haziran 2018 tarihinde sıra arası $70 \mathrm{~cm}$ ve sıra üzeri $20 \mathrm{~cm}$ olmak üzere pnömatik hassas ekim makinesi ile ekim gerçekleştirilmiştir. Çiçeklenme ve hasat dönemleri arasında $5 \mathrm{~kg} \mathrm{da}^{-1}$ olacak şekilde 2 doz gübreleme daha uygulanmıştır. Hayvan yemi olarak kullanılacağı için kimyasal mücadele uygulanmamış, tüm yetişme periyodu boyunca ortaya çıkan yabancı otlarla mücadele elle yapılmıştır.

\subsection{Insansız hava araçları görüntülerinin alınması}

Çalışmada kullanılan İHA platformu, ISUBÜ Ziraat Fakültesi Toprak Bilimi ve Bitki Besleme Bölümü Uzaktan Algılama ve Coğrafi Bilgi Sistemleri laboratuvarı envanterine 2017 yılında dahil edilen DJI Phantom 4 Pro Quadcopter (DJI, 2021) marka olup SHGM sisteminde kayıtll ve Türk Hava Sahası içerisinde kullanılabilmektedir. İHA platformu üzerine Sentera Double 4K Multispektral sensör (Sentera, 2021) yerleştirilmiş durumdadır (Demir ve Başayiğit, 2020).

Sentera FieldAgent yazılımı ile tüm çalışma alanını kapsayacak şekilde, \%70 bindirmeli, $10 \mathrm{mhp}$ hızda olacak şekilde ve $+70^{\circ}$ uçuş yönünde olacak şekilde uçuş planı yapılmıştır. Uçuşlar 01.07.2018, 15.07.2018, 30.07.2018, 15.08.2018 tarihlerinde 12:00-14:00 saatleri arasinda bulutsuz havada gerçekleştirilmiştir. 21 adet yer kontrol noktası verisi doğruluk değerlendirmesi için RTK GNSS GPS ile alınmıştır.

\subsection{Veri işleme ve analizler}

Uçuş planına göre 15 Ağustos 2018 tarihine kadar, İHA platformu üzerinde bulunan sensör tarafından kayıt edilen görüntülerde, tarımsal üretim için bilgi üretmek amacı ile Pix4D (demo), Erdas IMAGINE ve ArcGIS yazılımı kullanılarak görüntü işleme çalışmaları yapılmıştır. Verilerin analizinde vejetasyon indeksleri kullanılmışıı (Tablo 2). Çalışmada kullanılan indekslerin kısıtlı sulama uygulaması yapılan iki farklı sulama yönteminde üretilen tematik katmanlarda parsel bazlı olarak 3 tekerrürlü olarak ArcGIS programında zonal istatistik aracı kullanılarak ortalama indeks değerleri üretilmiştir. Elde edilen parsellerin indeks değerlerinin ayrı ayrı kısıtlı sulama uygulamasını belirlemede dönemsel ve parsel bazlı kullanılabilirliği araştırılmıştır.

Tablo 2. Vejetasyon indeksleri

\begin{tabular}{|c|c|c|}
\hline Vejetasyon İndeksi & Kullanılan Eşitlik & Kaynak \\
\hline $\begin{array}{l}\text { Normalleştirilmiş Fark Bitki Örtüsü } \\
\text { İndeksi } \\
\text { (Normalized difference vegetation index) }\end{array}$ & $\mathrm{NDVI}=\left(\frac{(\text { Near Infrared }- \text { Red })}{\text { Near Inrared }+ \text { Red }}\right)$ & Rouse ve ark., (1974) \\
\hline $\begin{array}{l}\text { Normalleştirilmiş Fark Kırmızı Kenar } \\
\text { İndeksi } \\
\text { (Normalized Difference Red Edge Index) }\end{array}$ & $N D R E=\left(\frac{(N I R-R e d \text { edge })}{N I R+\text { Red edge }}\right)$ & $\begin{array}{l}\text { Gitelson ve Merzlyak, } \\
\text { (1994) }\end{array}$ \\
\hline $\begin{array}{l}\text { Yaprak Klorofil İndeksi } \\
\text { (Leaf Chlorophyll Index) }\end{array}$ & $L C I=((N I R-\operatorname{Red} E d g e) /(N I R+R e d))$ & Datt ve ark., (2003) \\
\hline $\begin{array}{l}\text { Modifiye Klorofil Absorpsiyon Yansitma } \\
\text { Indeksi } \\
\text { (Modified Chlorophyll Absorption } \\
\text { Reflectance Index) }\end{array}$ & $\begin{aligned} \mathrm{MCARI}=\lfloor(\mathrm{NIR}- & \text { Red })-0.2(\mathrm{NIR} \\
& - \text { Green }\rfloor(\mathrm{NIR} / \mathrm{Red})\end{aligned}$ & $\begin{array}{l}\text { Daughtry ve ark., } \\
\qquad(2000)\end{array}$ \\
\hline $\begin{array}{c}\text { Üçgen Yeşillik İndeksi } \\
\text { (Triangular Greenness Index) }\end{array}$ & $T G I=($ Green $-0.39 *$ Red $-0.61 *$ Blue $)$ & Hunt ve ark., (2013) \\
\hline $\begin{array}{l}\text { Görünür Atmosferik Direnç İndeksi } \\
\text { (Visible Atmospheric Resistant Index) }\end{array}$ & $\begin{array}{c}V A R I=(((\text { Green }- \text { Red })) /(\text { Green }+ \text { Red } \\
- \text { Blue }))\end{array}$ & Gitelson ve ark., (2002) \\
\hline $\begin{array}{c}\text { Yeşil Normalleştirilmiş Fark Bitki } \\
\text { Örtüsü İndeksi } \\
\text { (Green Normalized Difference } \\
\text { Vegetation Index) }\end{array}$ & $G N D V I=\left(\frac{(N I R-\text { Green })}{(\text { NIR }+ \text { Green })}\right)$ & Gitelson ve ark., (1996) \\
\hline $\begin{array}{l}\text { Yeşil-Kırmızı Vejetasyon Endeksi } \\
\text { (Green-Red Vegetation Index) }\end{array}$ & $G R V I=\left(\frac{(\text { Green }- \text { Red })}{(\text { Green }+ \text { Red })}\right)$ & Tucker, (1979) \\
\hline $\begin{array}{l}\text { Toprak Uyarlanmış Vejetasyon İndeksi } \\
\text { (Soil Adjusted Vegetation Index) }\end{array}$ & $S A V I=\left(\frac{(N I R-R e d)}{(N I R+\operatorname{Red}+L)}\right)(1+L)$ & Huete, (1988) \\
\hline
\end{tabular}




\subsection{Görüntülerin doğruluk değerlendirmesi}

Doğruluk değerlendirmesi, İHA görüntüsünün düzenlenmesi ile ilgili hatayı tahmin etmektedir. Her bir ortomozaik konumlamanın kök ortalama kare hatası (RMSE) uzaysal doğruluğunu değerlendirmek için yaygın olarak kullanılmaktadır (Gómez-Candón ve ark., 2014; Boon ve ark., 2016). RMSE, ortomozaik görüntünün kalitesinin küresel bir göstergesini, görüntü koordinatlarının ve zemin koordinatlarının kalıntılarına dayanmaktadır (Eş. 1). Doğrulama puanına sahip bir görüntü için RMSE aşağıdaki eşitlikten hesaplanmaktadır (ERDAS, 1999):

$$
R M S E=\left[\frac{1}{n} \sum_{i=1}^{n}\left[\left(X_{s}-X_{r}\right)^{2}+\left(Y_{s}-Y_{r}\right)^{2}\right]\right]^{1 / 2}
$$

Eşitlikte; $X_{\mathrm{s}}$ ve $Y_{\mathrm{s}}$, İHA sensör görüntüsünün jeo-uzamsal nokta koordinatlarıdır. $X_{\mathrm{r}}$ ve $Y_{\mathrm{r}}$, saha seviyesinde ölçülen aynı GNSS-GPS noktasının koordinatlarıdır (Demir ve Başayiğit, 2020).

\section{7. İstatistiksel Analiz}

Çalışmada vejetasyon indekslerinin tanımlayıcı istatistikleri 4 dönemde hesaplanarak boxplot grafik özeti düzenlenmiştir. Ayrıca 9 vejetasyon indeksinin 4 dönemde sulama programları parsellerindeki değişimini gösteren Time Series Plot grafiği hazırlanmıştır. Çalışmada üzerinde durulan özellikler bakımından elde edilen veriler faktöriyel düzende tekrarlanan ölçümlü varyans analizi tekniği ile analiz edilmiştir (Gezan ve Carvalho, 2018). Çalışmada sulama programının 7 seviyesi ve vejetasyon indeksi ölçüm metodu faktörünün 4 dönemi aynı anda denenmiştir. Tekrarlanan ölçümler vejetasyon indeksi ölçüm metodunun seviyelerinde gerçekleştirilmiştir. Varyans analizi sonrası faktörlerin alt grup ortalamaları ve grup ortalamaları arasındaki farklılıkların belirlenmesinde çoklu karşılaştırma yöntemlerinden Tukey Testi kullanılmıştır.

\section{Bulgular}

\subsection{Veri toplama, ön işleme ve bitki indeksleri}

Çalışma alanında İHA ile yapılan görüntülemeler $15^{\prime}$ er gün arayla 4 farklı tarihte gerçekleştirilmiştir. Alanda belirlenen 21 yer kontrol noktası kullanılarak görüntülerin doğruluk değerlendirilmesi hesaplanmıştır (Tablo 3). Pix4D (Demo) yazılımı kullanılarak çalışma alanının görüntü mozaikleri oluşturulmuştur. Çalışma alanına ait multispektral görüntüler işlenerek 9 tane vejetasyon indeksine ait veriler oluşturulmuştur. Çalışma alanından kayıt edilen 4 görüntüden türetilen NDVI, NDRE, LCI, MCARI, TGI, VARI, GNDVI, GRVI ve SAVI indekslerindeki değişim sunulmuştur (Şekil 3).

Tablo 3. Çalışma alanı mozaik görüntülerinin jeo-uzamsal doğruluğu

\begin{tabular}{|c|c|c|c|c|c|}
\hline Uçuş Tarihi & $X(m)$ & $\mathbf{Y}(\mathbf{m})$ & $\mathrm{Z}(\mathbf{m})$ & $\begin{array}{c}\text { Doğruluk } \\
\text { RMSE (m) }\end{array}$ & $\begin{array}{c}\begin{array}{c}\text { Kappa } \\
\text { (derece) }\end{array} \\
\end{array}$ \\
\hline $\begin{array}{c}\text { 1.Dönem } \\
\text { (01.07.2018- 30.gün) }\end{array}$ & 0.24 & 0.15 & 0.33 & 0.24 & 0.011 \\
\hline $\begin{array}{c}\text { 2. Dönem } \\
\text { (15.07.2018 - 45.gün) }\end{array}$ & 0.40 & 0.25 & 0.27 & 0.31 & 0.010 \\
\hline $\begin{array}{c}\text { 3. Dönem } \\
\text { (30.07.2018-60.gün) }\end{array}$ & 0.33 & 0.27 & 0.48 & 0.36 & 0.008 \\
\hline $\begin{array}{l}\text { 4. Dönem } \\
\text { (15.08.2018- 76. gün) }\end{array}$ & 0.36 & 0.33 & 0.57 & 0.42 & 0.009 \\
\hline
\end{tabular}

Bitki indekslerine ait görüntülerin istatistik olarak karşılaştırılması amacıyla, sınır etkisini ortadan kaldırmak üzere parsel sınırlarında 2 metrelik bufferzone oluşturulmuş ve parsel içerisinde kalan $15.69 \mathrm{~m}^{2}$ alan ArcGIS ortamına aktarılmıştır. Daha sonra ArcGIS yazılımında zonal istatistik tool kullanılarak belirlenen alandaki 63 pikselin vejetasyon indeks değerlerinin ortalaması elde edilmiştir 
(Rhew ve ark., 2011). Yüzey altı ve yüzey üstü damla sulama yöntemi için uygulanan sulama programlarının değerlendirmesi insansız hava araçları kullanılarak elde edilen vejetasyon indeksleri ile yorumlamada kullanılmıştır. Üretilen bitki indeks görüntülerine göre parselleri oluşturan bitkilerin farklı dönemlerdeki gelişimleri indeks gruplarında farklılık göstermiştir.

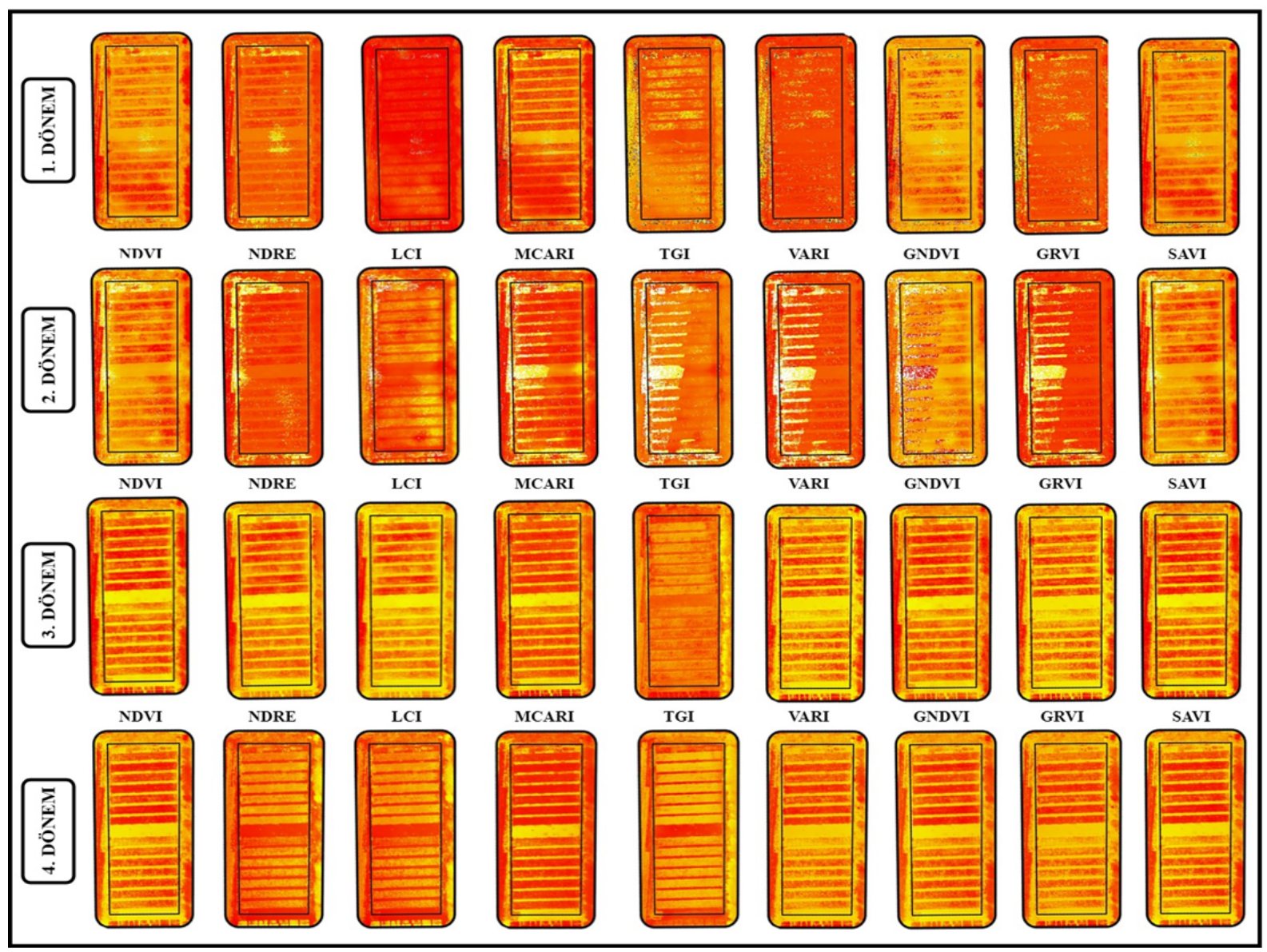

Şekil 1. Çalışma alanı temporal indeks değerleri.

\subsection{Yüzey altı damlama sulama yöntemi}

1. ve 2. dönemlerde mısır bitkisinin vejetatif gelişiminin az ve kaplama oranının düşük olması nedeniyle topraktan kaynaklanan yansıma baskın olmuştur. Bu dönemlerde 9 vejetasyon indeksi sulama programları için istatistiksel olarak önemli bulunmamıştır.

3. ve 4. dönemde yalnızca S6 (0.25) sulama programının uygulandığ 1 parselde bitki indeks değeri tekerrürler arası değişimi fazladır. S6 (0.25) sulama programının, S7 (0.00) sulama programından ortalama piksel değeri aralığının daha yüksek çıkması, belirlenen alandaki piksel değerlerinin, toprak yansıma değerinin yüksek olmasından kaynaklanmıştır. Diğer sulama programı uygulanan parsellerin vejetasyon indeks değerlerinde tekerrürler arasında deneme başına hata düşük olduğunu göstermiştir.

4. dönemde bitki yeşil aksamındaki gelişim hızı ve yüksek kapama oranından dolayı S6 dışındaki paraleller arası yakın değerler alarak deneme başına hata düşmüştür. Sulama programlarına ait vejetasyon indekslerinin 4 dönemdeki değişimi Şekil 4'te verilmiştir. Vejetasyon indisinin 4 dönemdeki değişimi Şekil 5'te gösterilmiştir. TGI ve LCI vejetasyon indeksi hariç diğer indeksler 4 dönemde lineer artış göstermiştir. NDVI, NDRE indeksine göre sulama programları arasında düşük lineer ilişki tespit edilmiştir. NDRE indeksinden dönemsel olarak daha başarılı sonuçlar elde edilmesi daha önceki yapılan benzer çalışmalarla örtüşmektedir (Becker ve ark., 2020). Çalışma alanına ait SAVI değerleri -0.51-0.94 aralığında değer almıştır. Yüzey altı damla sulama parsellerinin 3. dönem ortalama indeks değeri 0.45 olarak hesaplanmıştır. Taghvaeian ve ark. (2012)'e göre Mısır 0,64 SAVI değerinde tam örtüye ulaşmaktadır. 
LCI indeksine ait sulama programları ve dönem farklılıkları Tablo 4'te, TGI indeksine ait sulama programları ve dönem farklılıkları Tablo 5'te, diğer indekslerin dönemsel farklılıkları Tablo 6' da sunulmuştur.
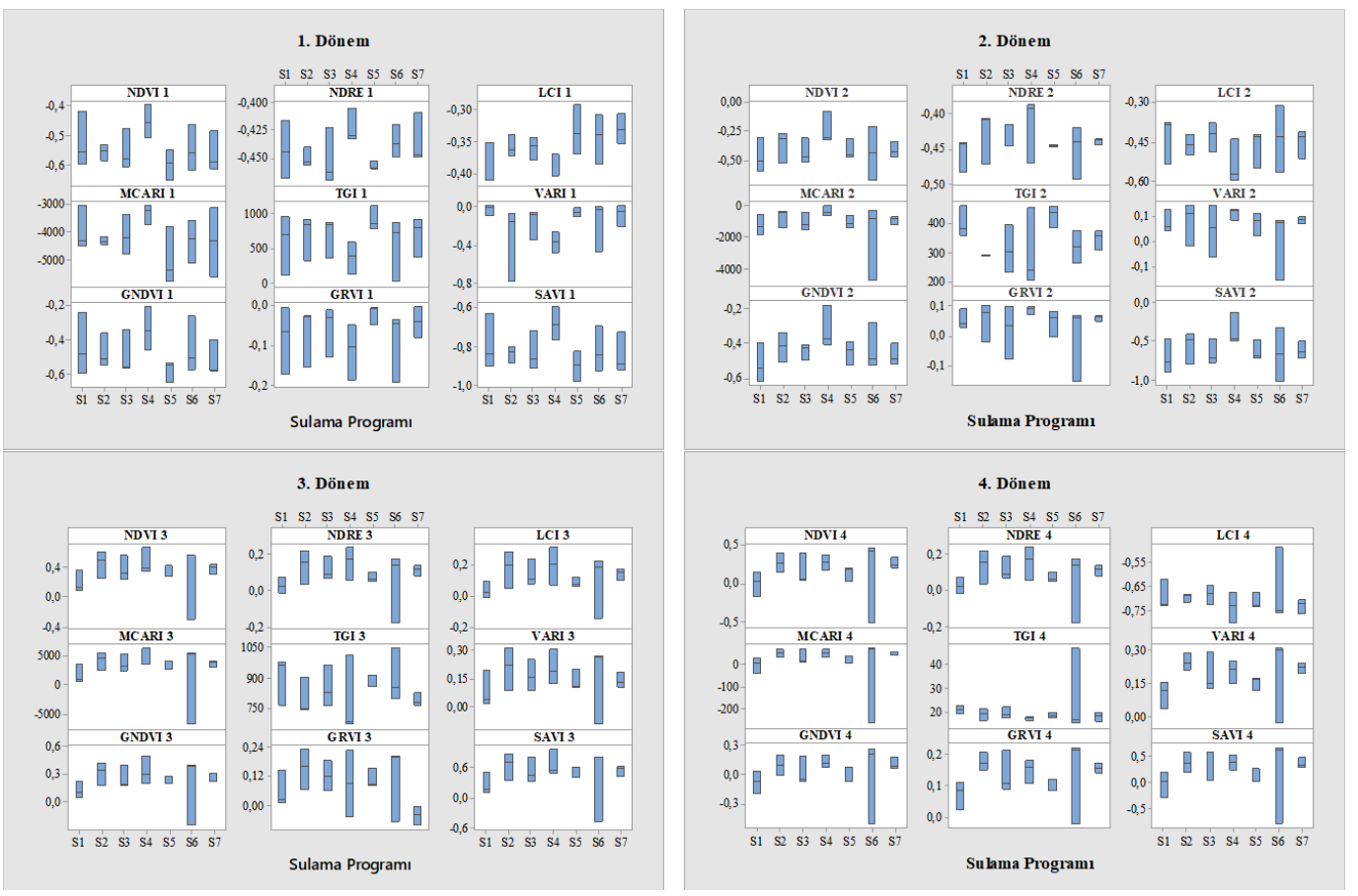

Şekil 4. Sulama Programlarına ait vejetasyon indekslerinin dönemsel tanımlayıcı istatistikleri.

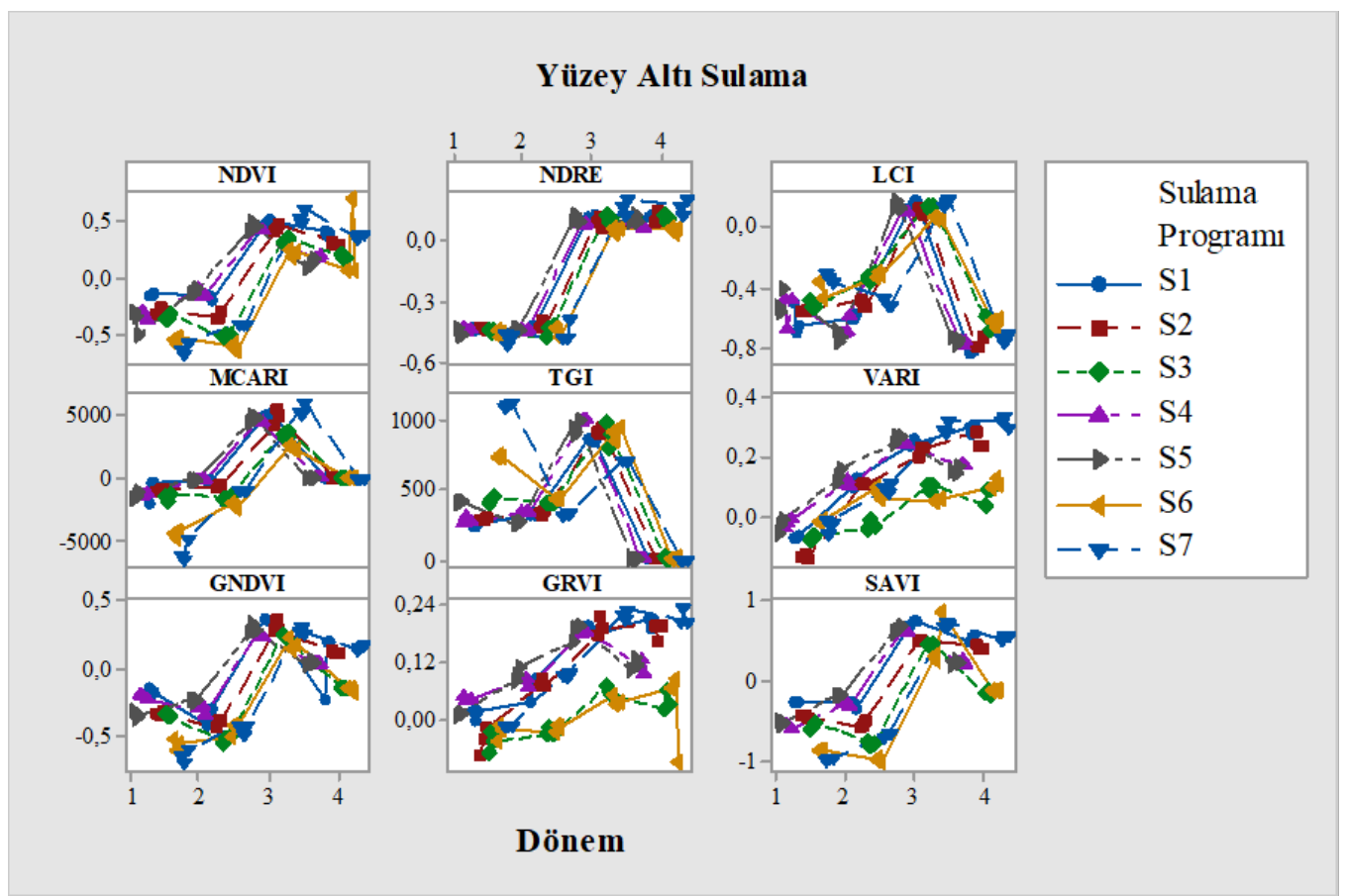

Şekil 2. Sulama Programlarının dönemsel vejetasyon indeks değerleri. 
Tablo 4. LCI indeksine Sulama Programlarının etkileri

\begin{tabular}{ccccc}
\hline Sulama Programı & $\begin{array}{c}\text { Dönem 1 } \\
\text { LCI1 } \\
\text { Ort. } \pm \text { Std. Hata }\end{array}$ & $\begin{array}{c}\text { Dönem 2 } \\
\text { LCI2 } \\
\text { Ort. } \pm \text { Std. Hata }\end{array}$ & $\begin{array}{c}\text { Dönem 3 } \\
\text { LCI3 } \\
\text { Ort. } \pm \text { Std. Hata }\end{array}$ & $\begin{array}{c}\text { Dönem 4 } \\
\text { LCI4 } \\
\text { Ort. } \pm \text { Std. Hata }\end{array}$ \\
\hline S1 & $-0.62 \pm 0.048 \mathrm{Bd}$ & $-0.57 \pm 0.055 \mathrm{Bc}$ & $0.11 \pm 0.064 \mathrm{Aab}$ & $-0.76 \pm 0.052 \mathrm{CBb}$ \\
S2 & $-0.50 \pm 0.048 \mathrm{Bc}$ & $-0.55 \pm 0.055 \mathrm{Cb}$ & $0.13 \pm 0.064 \mathrm{Aa}$ & $-0.77 \pm 0.052 \mathrm{Db}$ \\
S3 & $-0.52 \pm 0.048 \mathrm{Cc}$ & $-0.37 \pm 0.055 \mathrm{Ba}$ & $0.03 \pm 0.064 \mathrm{Ab}$ & $-0.60 \pm 0.052 \mathrm{Da}$ \\
S4 & $-0.56 \pm 0.048 \mathrm{Bcd}$ & $-0.67 \pm 0.055 \mathrm{Cd}$ & $0.07 \pm 0.064 \mathrm{Aab}$ & $-0.78 \pm 0.052 \mathrm{Db}$ \\
S5 & $-0.51 \pm 0.048 \mathrm{Bc}$ & $-0.69 \pm 0.055 \mathrm{Cb}$ & $0.13 \pm 0.064 \mathrm{Aa}$ & $-0.75 \pm 0.052 \mathrm{Cb}$ \\
S6 & $-0.40 \pm 0.048 \mathrm{Bb}$ & $-0.36 \pm 0.055 \mathrm{Ba}$ & $0.02 \pm 0.064 \mathrm{Ab}$ & $-0.60 \pm 0.052 \mathrm{Ca}$ \\
S7 & $-0.33 \pm 0.048 \mathrm{Ba}$ & $-0.43 \pm 0.055 \mathrm{Ca}$ & $0.10 \pm 0.064 \mathrm{Aab}$ & $-0.63 \pm 0.052 \mathrm{Da}$ \\
\hline
\end{tabular}

* Büyük harfler her bir sulama programın da vejetasyon indeksler arası farklılığı, küçük harfler ise her bir vejetasyon indeksinde sulama programları arası farklılı̆̆ göstermektedir $(\mathrm{p}<0.05)$.

Sulama programları 1. Dönemde, S7 ile S1, S2, S3, S4, S5 ve S6 arasındaki fark istatistiksel olarak farklı bulunmuştur. 2. Dönemde, S7 sulama programı ile S1, S2, S4 ve S5 sulama programları arasında istatistiksel fark önemli bulunmuştur. 3. dönemde diğer dönemlere göre LCI indeksinin istatistiksel fark1 önemli bulunmuştur. 3. Dönemde, sulama programları seviyesinde S2 ve S5, S3 ve S6 arasındaki fark istatistiksel olarak önemli bulunmuştur. 4. Dönemde, S7 sulama programı ile S1, S2, S4 ve S5 arasındaki fark önemli bulunmuştur. ET0 Penman Monteith yöntemine göre uygulanan deneme konularında LCI vejetasyon indeksi ile her dönemde S2, S4 ve S5 kontrole göre farklı bulunmuştur. Bu parsellere uygulanan sulama suyu miktarlarını her dönemde izlenmesinde başarılı şekilde kullanılabileceği belirlenmiştir. Zonal istatistiksel değerler kullanılarak bu ayrımın yapılabilmesi yaygın şekilde kullanımına olanak sağlamıştır. Mısır bitkisinde gelişme dönemine göre uygulanan deneme konularında başarılı bir şekilde izlenebileceği belirlenmiştir (Tablo 4).

Tablo 5. TGI indeksine Sulama Programlarının etkileri

\begin{tabular}{ccccc}
\hline $\begin{array}{c}\text { Sulama } \\
\text { Programı }\end{array}$ & $\begin{array}{c}\text { Dönem1 } \\
\text { TGI 1 } \\
\text { Ort. } \pm \text { Std. Hata }\end{array}$ & $\begin{array}{c}\text { Dönem 2 } \\
\text { TGI 2 } \\
\text { Ort. } \pm \text { Std. Hata }\end{array}$ & $\begin{array}{c}\text { Dönem 3 } \\
\text { TGI 3 } \\
\text { Ort. } \pm \text { Std. Hata }\end{array}$ & $\begin{array}{c}\text { Dönem 4 } \\
\text { TGI 4 } \\
\text { Ort. } \pm \text { Std. Hata }\end{array}$ \\
\hline S1 & $316.3 \pm 81.81 \mathrm{Bd}$ & $332.4 \pm 148,89 \mathrm{Bab}$ & $852.0 \pm 49.8 \mathrm{Aa}$ & $19.6 \pm 5.12 \mathrm{Ca}$ \\
S2 & $427.9 \pm 81.81 \mathrm{Bd}$ & $510.3 \pm 148,89 \mathrm{Bb}$ & $890.6 \pm 49.8 \mathrm{Aa}$ & $27.3 \pm 5.12 \mathrm{Ca}$ \\
S3 & $427.9 \pm 81.81 \mathrm{Bcd}$ & $510.3 \pm 148,89 \mathrm{Ba}$ & $890.6 \pm 49.8 \mathrm{Aa}$ & $27.3 \pm 5.12 \mathrm{Ca}$ \\
S4 & $314.7 \pm 81.81 \mathrm{Bd}$ & $330.9 \pm 148,89 \mathrm{Bab}$ & $1022.3 \pm 49.8 \mathrm{Aa}$ & $20.6 \pm 5.12 \mathrm{Ca}$ \\
S5 & $536.7 \pm 81.81 \mathrm{Bc}$ & $287.5 \pm 148,89 \mathrm{Cb}$ & $938.8 \pm 49.8 \mathrm{Aa}$ & $19.2 \pm 5.12 \mathrm{Da}$ \\
S6 & $758.7 \pm 81.81 \mathrm{Bb}$ & $307.1 \pm 148,89 \mathrm{Cb}$ & $898.1 \pm 49.8 \mathrm{Aa}$ & $23.8 \pm 5.12 \mathrm{Da}$ \\
S7 & $1036.8 \pm 81.81 \mathrm{Aa}$ & $-59.7 \pm 148,89 \mathrm{Bc}$ & $924.6 \pm 49.8 \mathrm{Aa}$ & $28.5 \pm 5.12 \mathrm{Ba}$ \\
\hline
\end{tabular}

* Büyük harfler her bir sulama programın da vejetasyon indeksler arası farklılığı, küçük harfler ise her bir vejetasyon indeksinde sulama programları arası farklılığı göstermektedir $(\mathrm{p}<0.05)$.

Sulama programları 1. dönemde, S3 ile S5 ve S6 sulama programı arasındaki fark istatistiksel olarak önemli bulunmuştur. 2. dönemde, $\mathrm{S} 7$ sulama programı ile diğer sulama programları arasındaki fark önemli bulunmuştur. 2. dönemde, S7 sulama programı ile diğer sulama programlarında istatistiksel fark önemli bulunmuştur. 1. dönemde, S7 sulama programı ile diğer sulama programları arasında istatistiksel fark önemli bulunmuştur. 2. dönemde, S3 ile S2, S5 ve S6 sulama programı arasındaki fark istatistiksel olarak önemli bulunmuştur. Bu parsellere uygulanan sulama suyu miktarlarını 1. ve 2 . dönemde izlenmesinde başarılı şekilde kullanılabileceği belirlenmiştir. Zonal istatistiksel değerlerin kullanılarak bu ayrımın yapılabilmesi yaygın şekilde kullanımına olanak sağlamıştır. Mısır bitkisinde 1 . ve 2. dönemine göre uygulanan deneme konularında başarılı bir şekilde izlenebileceği belirlenmiştir. 3 . ve 4. dönemde TGI vejetasyon indeksi deneme konularına göre ayrımda sınırlı kalmıştır. Bu durumun zonal istatistik değerlerin kullanılmasından kaynaklandığı düşünülmektedir (Tablo 5). 
Tablo 6. Vejetasyon indekslerine Sulama Programlarının dönemsel etkileri

\begin{tabular}{lllll}
\hline $\begin{array}{l}\text { VEJETASYON } \\
\text { İNDEKSİ }\end{array}$ & $\begin{array}{l}\text { DÖNEM 1 } \\
\text { Ort. } \pm \text { Std. Hata }\end{array}$ & $\begin{array}{l}\text { DÖNEM 2 } \\
\text { Ort. } \pm \text { Std. Hata }\end{array}$ & $\begin{array}{l}\text { DÖNEM 3 } \\
\text { Ort. } \pm \text { Std. Hata }\end{array}$ & $\begin{array}{l}\text { DÖNEM 4 } \\
\text { Ort. } \pm \text { Std. Hata }\end{array}$ \\
\hline NDVI & $-0.40 \pm 0.021 \mathrm{C}$ & $-0.34 \pm 0.035 \mathrm{~B}$ & $0.30 \pm 0.064 \mathrm{~B}$ & $0.07 \pm 0.064 \mathrm{~A}$ \\
NDRE & $-0.45 \pm 0.004 \mathrm{~B}$ & $-0.44 \pm 0.006 \mathrm{~B}$ & $0.06 \pm 0.022 \mathrm{~A}$ & $0.06 \pm 0.022 \mathrm{~A}$ \\
MCARI & $-2528.4 \pm 243.1 \mathrm{C}$ & $-1295.2 \pm 407.7 \mathrm{BC}$ & $2687.6 \pm 863.9 \mathrm{~A}$ & $-1.7998 \pm 22.99 \mathrm{~B}$ \\
VARI & $-0.06 \pm 0.013 \mathrm{~B}$ & $0.02 \pm 0.049 \mathrm{~B}$ & $0.15 \pm 0.029 \mathrm{~A}$ & $0.16 \pm 0.024 \mathrm{~A}$ \\
GNDVI & $-0.39 \pm 0.021 \mathrm{C}$ & $-0.32 \pm 0.047 \mathrm{C}$ & $0.20 \pm 0.047 \mathrm{~A}$ & $-0.03 \pm 0.048 \mathrm{~B}$ \\
GRVI & $-0.01 \pm 0.011 \mathrm{C}$ & $0.0017 \pm 0.049 \mathrm{~B}$ & $0.11 \pm 0.021 \mathrm{~A}$ & $0.11 \pm 0.017 \mathrm{~A}$ \\
SAVI & $-0.61 \pm 0.032 \mathrm{C}$ & $0.51 \pm 0.052 \mathrm{C}$ & $0.45 \pm 0.096 \mathrm{~A}$ & $0.11 \pm 0.096 \mathrm{~B}$ \\
\hline
\end{tabular}

*Büyük harfler her bir vejetasyon indeksinin gelişme dönemindeki farklılığını göstermektedir $(\mathrm{p}<0.05)$.

Çalışmada üzerinde durulan özellikler bakımından elde edilen veriler faktöriyel düzende tekrarlanan ölçümlü varyans analizi tekniği ile analiz edilmiștir. Çalıșmada sulama programı faktörünün 7 seviyesi ve vejetasyon indeksi ölçüm metodu faktörünün 4 seviyesi aynı anda denenmiştir. Tekrarlanan ölçümler vejetasyon indeksi ölçüm metodunun seviyelerinde gerçekleştirilmiştir. LCI ve TGI vejetasyon indekslerinin sulama programlarına ve 4 dönemde istatistiksel olarak duyarlı olmasından dolayı kullanılabileceği belirlenmiştir (Tablo 7). Bunun nedeninin piksellerin ortalama değerlerinin kullanılmasından ve elde edilen değerlerin standart sapmalarının negatif ve pozitif değer almasından dolayı olduğu düşünülmektedir. Nitekim dönemsel olarak bitkilerin toprak yüzeyini kaplama oranı arttıkça vejetasyon indekslerinin kullanılabilirliğinin arttı̆̆ 2019; Zhang ve ark., 2021).

\subsection{Yüzey üstü damla sulama yöntemi}

Sulama programlarına ait 9 indeks değeri elde edilmiştir. Yüzey üstü damla sulama yöntemi uygulanan sulama programlarına ait tanımlayıcı istatistik değerleri Şekil 6'da verilmiştir. Elde edilen vejetasyon indeks değerleri 1. ve 2. dönemde negatif değerler almıştır. Bu dönemlerde mısır bitkisinin vejetatif gelişimi düşük olduğu için sulama programı paralellerinde topraktan kaynaklı yansıma düşük olduğu için ortalama zonal istatistik değerleri negatif değerler almıştır. Bu dönemlerde mısır bitkisinin kapama oranı düşük olduğu için, sulama programlarında vejetasyon indeks değerlerinin topraktan yansıma değerlerini içeren piksellerin fazla olmasından kaynaklanmıştır. 3. ve 4. dönemde S6 (0.25) sulama programı haricinde sulama programı uygulanan parsellerde negatif değerler elde edilmiştir. 4 . dönemde yüksek kapama oranından dolayı S6 dışında paraleller arası yakın değerler alarak deneme başına hata düşmüştür. Sulama programlarına ait vejetasyon indekslerinin 4 dönemdeki değişimi Şekil 7'de verilmiştir. TGI ve LCI vejetasyon indeksi hariç diğer indeksler 4 dönemde lineer artı̧̧ göstermiştir. NDVI, NDRE indeksine göre sulama programları arasında düşük lineer ilişki tespit edilmiştir. NDRE indeksinin dönemsel olarak daha başarılı sonuçlar vermesi daha önceki yapılan çalışmalar ile benzerlik ifade etmektedir (Becker ve ark., 2020). Çalışma alanına ait SAVI değerleri 0.10-0.89 aralığında değer almıştır. Yüzey altı damla sulama yönteminde sulama programları ve dönemsel VARI indeksine ait sonuçlar verilmiştir (Tablo 7). VARI indeksine ait sulama programları ve dönem farklılıkları Tablo 7'de sunulmuştur. Diğer bitki indekslerinin dönemsel farklılıkları Tablo 8'de gösterilmiştir $(\mathrm{p}<0.05)$. 
Tablo 7. VARI indeksine sulama programlarının etkileri

\begin{tabular}{ccccc}
\hline Sulama Programı & $\begin{array}{c}\text { Dönem 1 } \\
\text { VARI 1 } \\
\text { Ort. } \pm \text { Std. Hata }\end{array}$ & $\begin{array}{c}\text { Dönem 2 } \\
\text { VARI2 } \\
\text { Ort. } \pm \text { Std. Hata }\end{array}$ & $\begin{array}{c}\text { Dönem 3 } \\
\text { VARI 3 } \\
\text { Ort. } \pm \text { Std. Hata }\end{array}$ & $\begin{array}{c}\text { Dönem 4 } \\
\text { VARI 4 } \\
\text { Ort. } \pm \text { Std. Hata }\end{array}$ \\
\hline S1 & $-0.03 \pm 0.11 \mathrm{Aa}$ & $0.07 \pm 0.04 \mathrm{Aa}$ & $0.07 \pm 0.07 \mathrm{Aa}$ & $0.10 \pm 0.05 \mathrm{Aa}$ \\
S2 & $-0.33 \pm 0.11 \mathrm{Bc}$ & $0.08 \pm 0.04 \mathrm{Aa}$ & $0.206 \pm 0.07 \mathrm{Aa}$ & $0.24 \pm 0.05 \mathrm{Aa}$ \\
S3 & $-0.16 \pm 0.11 \mathrm{Babc}$ & $0.05 \pm 0.04 \mathrm{Aba}$ & $0.16 \pm 0.07 \mathrm{Aa}$ & $0.19 \pm 0.05 \mathrm{Aa}$ \\
S4 & $-0.37 \pm 0.11 \mathrm{Bbc}$ & $0.11 \pm 0.04 \mathrm{Aa}$ & $0.206 \pm 0.07 \mathrm{Aa}$ & $0.208 \pm 0.05 \mathrm{Aa}$ \\
S5 & $-0.05 \pm 0.11 \mathrm{Aa}$ & $0.07 \pm 0.04 \mathrm{Aa}$ & $0.13 \pm 0.07 \mathrm{Aa}$ & $0.15 \pm 0.05 \mathrm{Aa}$ \\
S6 & $-0.16 \pm 0.11 \mathrm{Babc}$ & $0.01 \pm 0.04 \mathrm{Aa}$ & $0.14 \pm 0.07 \mathrm{Aa}$ & $0.19 \pm 0.05 \mathrm{Aa}$ \\
S7 & $-0.08 \pm 0.11 \mathrm{Bab}$ & $0.08 \pm 0.04 \mathrm{ABa}$ & $0.13 \pm 0.07 \mathrm{ABa}$ & $0.22 \pm 0.05 \mathrm{Aa}$ \\
\hline
\end{tabular}

* Büyük harfler her bir sulama programın da dönemler arası farklılığı, küçük harfler ise her bir dönemde sulama programı uygulanan parseller arası farklılığı göstermektedir $(\mathrm{p}<0.05)$.

Yüzey üstü damla sulama yönteminde sulama programları ve dönemsel VARI indeksine ait sonuçlar verilmiştir $(\mathrm{p}<0.05)$. Sulama programları S1, S5'te dönemler arası fark görülmemiştir. Sulama programı S3, S4, S5 ve S6'da 1. dönem ile 2. 3. 4. dönem arasındaki fark istatistiksel olarak önemli bulunmuştur. Sulama programı S7 4. Dönem ve 1. Dönem arasındaki fark önemli bulunmuştur. Sulama program1 S7 (kontrol)'e göre, 1. Dönem S2 sulama programı istatistiksel olarak fark önemli bulunmuştur. 3. ve 4. dönemde S7 (Kontrol) sulama programına göre sulama programı seviyelerinde istatistiksel olarak fark önemsiz çıkmıştır. 3. ve 4. dönemde VARI vejetasyon indeksi deneme konularına göre ayrımda sınırlı kalmıştır. Bu durumun zonal istatistik değerlerin kullanılmasından kaynaklandığı düşünülmektedir.
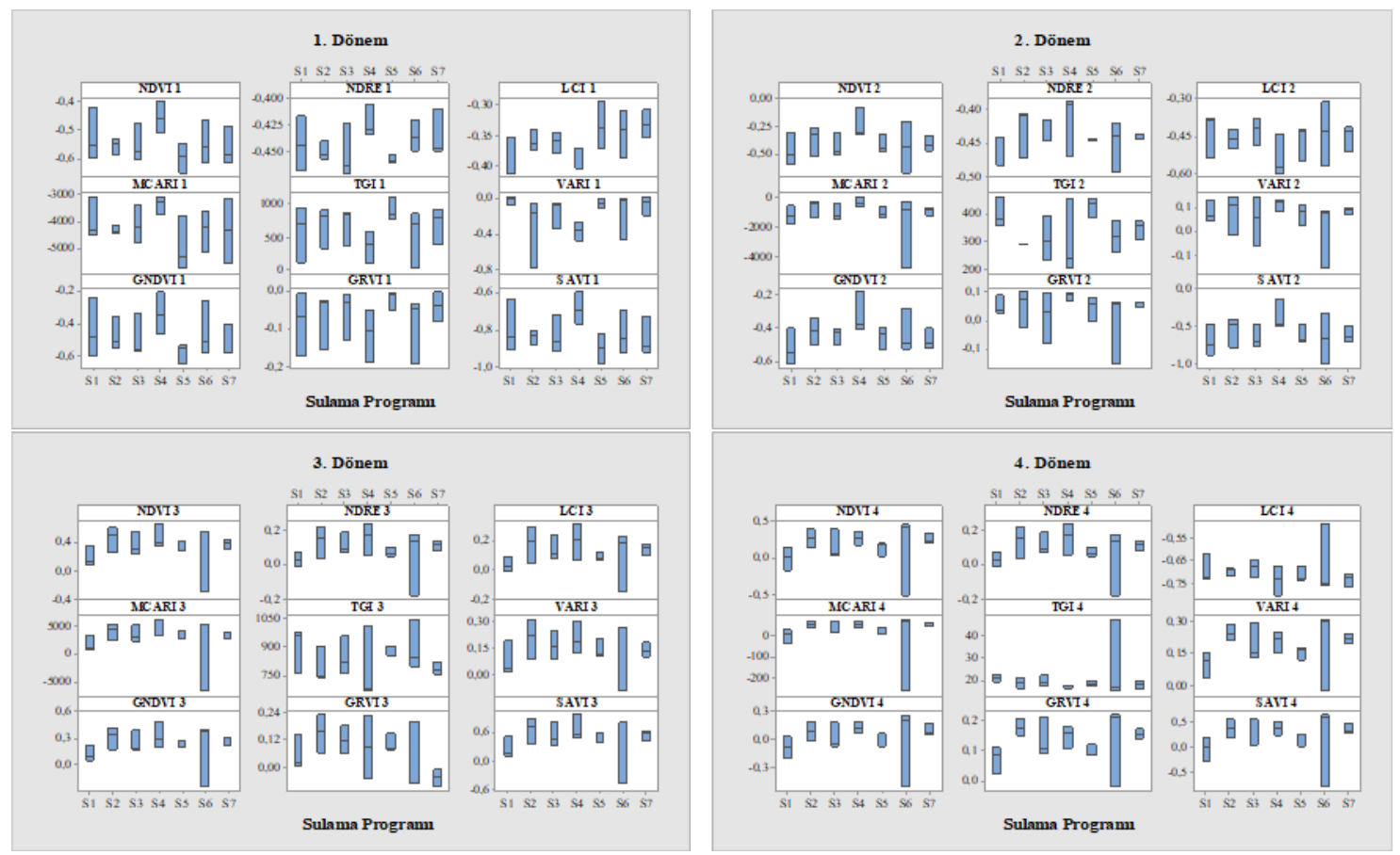

Şekil 6. Sulama Programlarına ait vejetasyon indekslerinin dönemsel tanımlayıcı istatistikleri. 


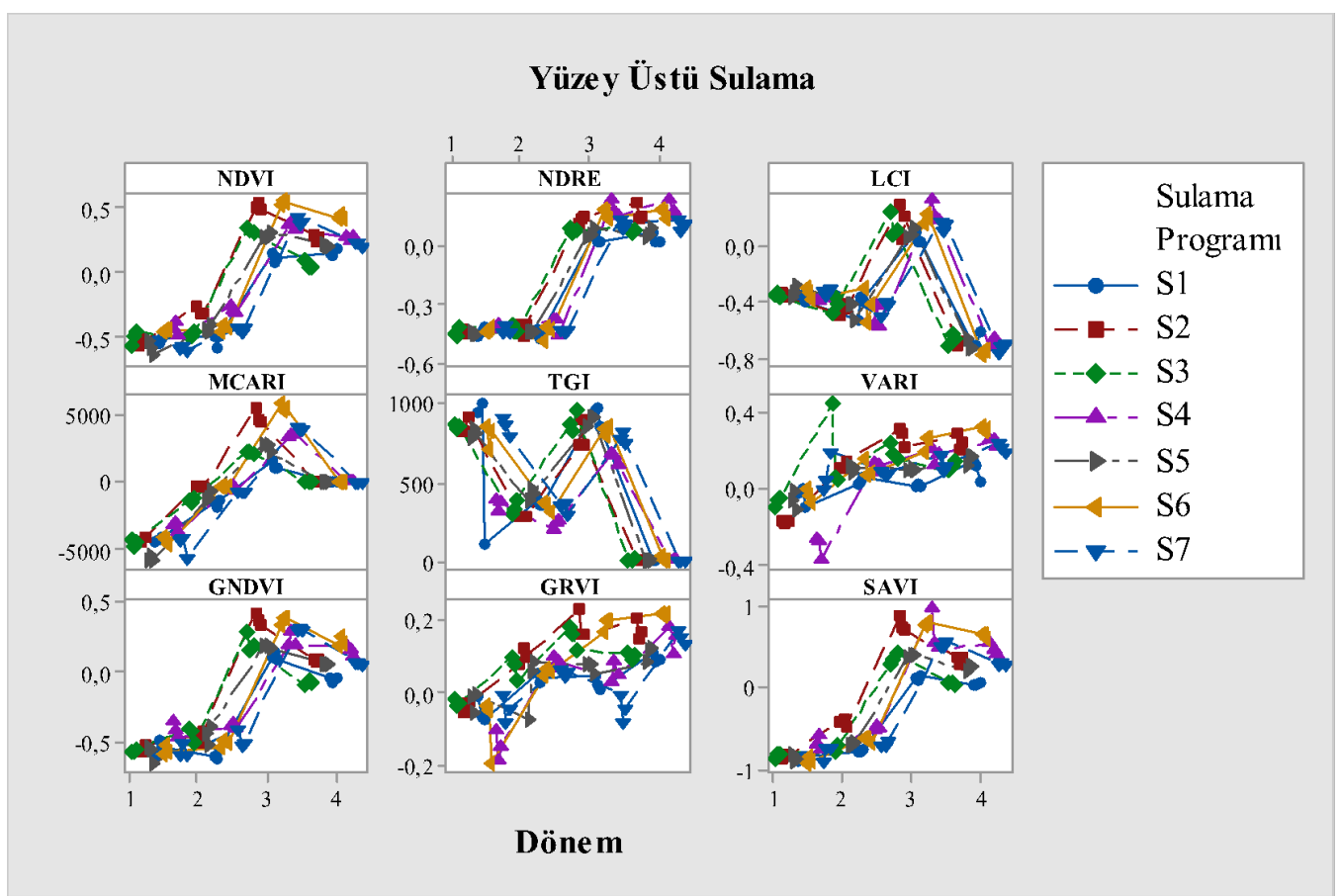

Şekil 7. Sulama Programlarının dönemsel vejetasyon indeks değerleri.

Tablo 8. Vejetasyon indekslerine sulama programlarının dönemsel etkileri

\begin{tabular}{ccccc}
\hline $\begin{array}{c}\text { VEJETASYON } \\
\text { INDEKSI }\end{array}$ & $\begin{array}{c}\text { DÖNEM 1 } \\
\text { Ort. } \pm \text { Std. Hata }\end{array}$ & $\begin{array}{c}\text { DÖNEM2 } \\
\text { Ort. } \pm \text { Std. Hata }\end{array}$ & $\begin{array}{c}\text { DÖNEM3 } \\
\text { Ort. } \pm \text { Std. Hata }\end{array}$ & $\begin{array}{c}\text { DÖNEM4 } \\
\text { Ort. } \pm \text { Std. Hata }\end{array}$ \\
\hline NDVI & $-0.54 \pm 0.015 \mathrm{~B}$ & $-0.39 \pm 0.031 \mathrm{~B}$ & $0.33 \pm 0.05 \mathrm{~A}$ & $0.16 \pm 0.053 \mathrm{~A}$ \\
NDRE & $-0.44 \pm 0.004 \mathrm{~B}$ & $-0.43 \pm 0.006 \mathrm{~B}$ & $0.09 \pm 0.021 \mathrm{~A}$ & $0.09 \pm 0.021 \mathrm{~A}$ \\
LCI & $0.357 \pm 0.006 \mathrm{~B}$ & $0.460 \pm 0.017 \mathrm{C}$ & $0.123 \pm 0.024 \mathrm{~A}$ & $0.704 \pm 0.016 \mathrm{D}$ \\
MCARI & $-4208.2 \pm 176.4 \mathrm{C}$ & $-1038.5 \pm 224.1 \mathrm{~B}$ & $3136.7 \pm 636.5 \mathrm{~A}$ & $24.50 \pm 16.80 \mathrm{~B}$ \\
TGI & $637.8 \pm 70.3 \mathrm{~B}$ & $342.3 \pm 15.1 \mathrm{C}$ & $844.5 \pm 24.7 \mathrm{~A}$ & $19.63 \pm 1.54 \mathrm{D}$ \\
GNDVI & $-0.47 \pm 0.028 \mathrm{C}$ & $0.43 \pm 0.021 \mathrm{C}$ & $0.24 \pm 0.038 \mathrm{~A}$ & $0.04 \pm 0.041 \mathrm{~B}$ \\
GRVI & $-0.06 \pm 0.015 \mathrm{C}$ & $0.04 \pm 0.015 \mathrm{~B}$ & $0.08 \pm 0.021 \mathrm{AB}$ & $0.13 \pm 0.014 \mathrm{~A}$ \\
SAVI & $-0.81 \pm 0.02 \mathrm{D}$ & $-0.59 \pm 0.046 \mathrm{C}$ & $0.50 \pm 0.075 \mathrm{~A}$ & $0.25 \pm 0.079 \mathrm{~B}$ \\
\hline
\end{tabular}

Dönemsel olarak elde edilen SAVI, TGI, LCI indekslerinin vejetasyon dönemini izlemede istatistiksel olarak anlamlı sonuçlar verdiği tespit edilmiştir. Diğer indekslerde için 1. ve 2. dönem ile 3 . ve 4. dönem arasında istatistiksel olarak farklılık önemli bulunmuştur $(p<0.05)$. Yeşil bandın yansıması sağlıklı bitki örtüsünün bir göstergesidir. Yeşil yansıma kapasitesinin kuraklık stresini tespit etme kapasitesinin bir sonucu olarak, bu bandı kullanan birkaç vejetasyon indeksi önerilmiştir (Zhang ve ark, 2019; Zhang ve ark., 2021). Bu çalışma için kullanılan yeşil spektral bant dahil NDVI, NDRE, LCI, MCARI, TGI, VARI, GNDVI, GRVI ve SAVI indekslerinin kisitl sulama uygulanan misir parsellerinde farklı sulama yöntemlerine göre etkileri değerlendirilmiştir. NDRE, Normalize Edilmiş Fark Vejetatif İndeksi (NDVI) ile hesaplamada yöntemi aynıdır. Ancak, NDVI'da kullanılan ortalama kırmızı bant yerine ortalama kırmızı kenar bandı kullanılmaktadır. Görünür bölge yansıma spektrumunun kırmızı kenarlı bölgesi, klorofilin radyasyonu absorbe etmediği bitki örtüsünün yansımasında hızlı artış gösteren bir bölge olduğu belirtilmektedir (Gitelson ve Merzlyak, 1994). Yakın kızılötesi ve görünür bölge bantlar ile üretilen vejetasyon indeksleri toprak yansıması da dikkate alınarak küçük işletmelerin arazilerindeki sulama seviyelerini ek bir düzeltme faktörü ihtiyacı hissetmeden belirlemede kullanılabileceği çalışma ile ortaya konulmuştur.

Çiftlik ölçeğinde, bitki su stresinin takibi genellikle zordur. Uydu ve uçak platformları ile uzaktan algılama, yüksek işletim zorluğu ve yüksek işletme maliyeti gibi dezavantajlara sahiptir ( Zhao, 2014; Han ve ark., 2018; Zhang ve ark., 2019; Müjdeci ve ark., 2020; Demir ve Başayiğit, 2020; Zhang 
ve ark., 2021). İnsansız hava aracı (IHHA) uzaktan algılama sistemi, mahsul bilgilerini istenen bir uzamsal ve zamansal çözünürlükte toplanması bitki su stresini ve su kısıtını çiftlik ölçeğinde hızlı ve titizlikle izlenmesine olanak sağlayacağı belirlenmiştir. Diğer uzaktan algılama yöntemlerine göre küçük ölçekli alanlarda yapılan tarımsal uygulamaları, İHA ile izlenmesi ve takip edilmesinde önemli avantajlara sahip olması tarımsal amaçlı kullanımlarının arttıracağını göstermektedir.

\section{Sonuç}

Bu çalışma ile, İHA platformlarındaki yüksek uzamsal çözünürlüğe sahip Multispektral sensör kullanılarak kısıtlı sulama uygulanan parsellerin multispektral görüntülerinden (B, G, R, RE, NIR) türetilen vejetasyon indeksleri ile farklı sulama yöntemlerinin izlenebilirliği ve tarımsal uygulamalarda kullanılabilirliği belirlenmiştir. Yüzey altı damla sulama yönteminde LCI ve TGI indeksleri, yüzey üstü damla sulama yönteminde VARI indeksi S7 (Kontrol) programına göre, diğer ET0'a göre hesaplanan sulama seviyelerindeki uygulanan sulama suyu miktarlarında mısır bitkisi için daha kullanışlı olduğu belirlenmiştir $(\mathrm{p}<0.05)$.

Standart Yağış İndeksi (SPI) ile hesaplanan Normale Yakın Kuraklık kategorisi içerisindeki ayların görüldüğü bölgeler için sulama yöntemlerinde ve sulama programlarında silajlık mısır gelişiminin takip edilmesi ve su ihtiyacı kritik seviyelerinin belirlenmesi çalışmalarının gerekliliğini ortaya koymak için uygulanan yaklaşımın kullanılabilir olduğu sonucuna varılmıştır.

Multispektral sensör bulunan İHA'lara sahip yerel çiftçiler için, silajlık mısır bitkisinin sulama seviyelerinde izlenmesi ve değerlendirmesini gerçekleştirmek için önemli sonuçlar ortaya konulmuştur. İHA sensörlerine belirtilen indeks değerini hesaplayan algoritmaların programlanması ile çiftçiler için daha kullanılabilir hale gelebileceği düşünülmektedir. Çalışmaların, sulama suyu seviyesi ve arazi koşullarında elde edilen verilerin değerlendirilmesinde dijital tarım teknikleri yönünden katkı sağlayacağı beklenmektedir. Nitekim bu çalışma, Akıllı Tarım, Hassas Tarım, Organik Tarım ve İyi Tarım uygulamalarında İHA kullanımlarına yönelik bir alternatif uygulama örneği olmuştur.

\section{Teşekkür}

Bu çalışmada, arazi verilerinin elde edilmesinde Prof. Dr. Yusuf UÇAR'a, Öğr. Gör. Mehmet ALAGÖZ'e ve Arş. Gör. Emre TOPÇU'ya yapmış oldukları desteklerinden dolayı teşekkür ederiz. Çalışma süresince desteğini esirgemeyen Ziraat Yük. Müh. Tuğba TİRYAKİye teşekkür ederiz. Sorumlu yazar Sinan DEMIR Organik Tarım alt alanında 100/2000 YÖK Doktora Bursiyeri’dir.

\section{Kaynakça}

Alaboz, P., Demir, S., \& Dengiz, O. (2020). Farkl1 Enterpolasyon Yöntemleri Kullanılarak Toprakların Nem Sabitelerine Ait Konumsal Dağılımların Belirlenmesi, Isparta Atabey Ovası Örneği. Tekirdă̆ Ziraat Fakültesi Dergisi, 17(3), 432-444.

Alaboz, P., \& Çakmakci, T. (2020). Effect of cocopeat application on field capacity and permanent wilting point in sandy loam and clay loam soil. Mediterranean Agricultural Sciences, 33(2), 285-290.

Becker, T., Nelsen, T. S., Leinfelder-Miles, M., \& Lundy, M. E. (2020). Differentiating between Nitrogen and Water Deficiency in Irrigated Maize Using a UAV-Based Multi-Spectral Camera. Agronomy, 10(11), 1671.

Boon, M. A., Greenfield, R., \& Tesfamichael, S. (2016). Wetland assessment using unmanned aerial vehicle (UAV) photogrammetry. In Proceedings of the International Archives of the Photogrammetry, Remote Sensing and Spatial Information Sciences, XXIII ISPRS Congress, Prague, Czech Republic (pp. 12-19).

Calera, A., Campos, I., Osann, A., D’Urso, G., \& Menenti, M. (2017). Remote sensing for crop water management: from ET modelling to services for the end users. Sensors, 17(5), 1104.

Çakmakc1, T., Sahin, Ü., Kiziloglu, F. M., Tüfenkci, S., Kuslu, Y., \& Erkus, F. S. (2017). Wastewater Treatment in Constructed Wetlands and Suggestions for the Use of Constructed Wetlands in Cold-Climate Regions. Yyü Tar Bil Derg, 27(4). 
Çakmakcı, T., \& Şahın, Ü. (2020). Arıtılmış Atık Suyun Farklı Sulama Yöntemleriyle Uygulanmasının Silajlık Mısırda Makro-Mikro Element ve Ağır Metal Birikimine Etkisi. Journal of Tekirdag Agricultural Faculty, 17(1), 12-23.

Danandeh Mehr, A., Sorman, A. U., Kahya, E., \& Hesami Afshar, M. (2020). Climate change impacts on meteorological drought using SPI ve SPEI: case study of Ankara, Turkey. Hydrological Sciences Journal, 65(2), 254-268.

Datt, B., McVicar, T. R., Van Niel, T. G., Jupp, D. L., \& Pearlman, J. S. (2003). Preprocessing EO-1 Hyperion hyperspectral data to support the application of agricultural indexes. IEEE Transactions on Geoscience and Remote Sensing, 41(6), 1246-1259.

Daughtry, C. S. T., Walthall, C. L., Kim, M. S., De Colstoun, E. B., \& McMurtrey Iii, J. E. (2000). Estimating corn leaf chlorophyll concentration from leaf and canopy reflectance. Remote Sensing of Environment, 74(2), 229-239.

Demir, S., \& Başayiğit, L. Sorunlu Gelişim Gösteren Bitkilerin İnsansız Hava Araçları (İHA) ile Belirlenmesi. Türk Bilim ve Mühendislik Dergisi, 2(1), 12-22.

DJI, 2021. DJI drone üreticisi (Phantom Serisi), Hong Kong. https://www.dji.com/support/product/phantom-4-pro. (Erişim tarihi: 02 Şubat 2021)

ERDAS (1999). ERDAS IMAGINE 8.2. field guide. Erdas INC. Atlanta, Georgia.

Fernández García, I., Lecina, S., Ruiz-Sánchez, M. C., Vera, J., Conejero, W., Conesa, M. R., ... \& Montesinos, P. (2020). Trends ve challenges in irrigation scheduling in the semi-arid area of Spain. Water, 12(3), 785.

Gezan, S. A., \& Carvalho, M. (2018). Analysis of repeated measures for the biological ve agricultural sciences. Applied Statistics in Agricultural, Biological and Environmental Sciences, 279-297.

Gitelson, A., \& Merzlyak, M. N. (1994). Quantitative estimation of chlorophyll-a using reflectance spectra: Experiments with autumn chestnut and maple leaves. Journal of Photochemistry and Photobiology B: Biology, 22(3), 247-252.

Gitelson, A. A., Kaufman, Y. J., \& Merzlyak, M. N. (1996). Use of a green channel in remote sensing of global vegetation from EOS-MODIS. Remote Sensing of Environment, 58(3), 289-298.

Gitelson, A. A., Stark, R., Grits, U., Rundquist, D., Kaufman, Y., \& Derry, D. (2002). Vegetation and soil lines in visible spectral space: a concept and technique for remote estimation of vegetation fraction. International Journal of Remote Sensing, 23(13), 2537-2562.

Gómez-Candón, D., De Castro, A. I., \& López-Granados, F. (2014). Assessing the accuracy of mosaics from unmanned aerial vehicle (UAV) imagery for precision agriculture purposes in wheat. Precision Agriculture, 15(1), 44-56.

Han, L., Yang, G., Yang, H., Xu, B., Li, Z., \& Yang, X. (2018). Clustering field-based maize phenotyping of plant-height growth and canopy spectral dynamics using a UAV remote-sensing approach. Frontiers in Plant Science, 9, 1638.

Huang, Y., Reddy, K. N., Fletcher, R. S., \& Pennington, D. (2018). UAV low-altitude remote sensing for precision weed management. Weed Technology, 32(1), 2-6.

Huete, A. R. (1988). A soil-adjusted vegetation index (SAVI). Remote sensing of environment, 25(3), 295-309.

Hunt Jr, E. R., Doraiswamy, P. C., McMurtrey, J. E., Daughtry, C. S., Perry, E. M., \& Akhmedov, B. (2013). A visible band index for remote sensing leaf chlorophyll content at the canopy scale. International Journal of Applied Earth Observation and Geoinformation, 21, 103-112.

Kumar, A., Taparia, M., Rajalakshmi, P., Guo, W., Naik, B., Marathi, B., \& Desai, U. B. (2020). Cig based stress identification method for maize crop using uav based remote sensing. In 2020 IEEE Sensors Applications Symposium (SAS), (pp. 1-6). IEEE.

McKee, T. B., Doesken, N. J., \& Kleist, J. (1993). The relationship of drought frequency and duration to time scales. In Proceedings of the 8th Conference on Applied Climatology, 17(22), 179-183.

MGM, 2021. Türkiye İklim İstatistikleri. Meteoroloji Genel Müdürlüğü, Ankara. https://www.mgm.gov.tr/veridegerlendirme/il-ve-ilceler-istatistik.aspx?m=ISPARTA (Erişim tarihi:02.02.2021)

Müjdeci, M., Demircioğlu, A. C., \& Alaboz, P. (2020). The effects of farmyard manure and green manure applications on some soil physical properties. Yüzüncü Yıl Üniversitesi Tarım Bilimleri Dergisi, 30(1), 9-17. 
Osakabe, Y., Osakabe, K., Shinozaki, K., \& Tran, L. S. P. (2014). Response of plants to water stress. Frontiers in Plant Science, 5, 86.

Rhew, I. C., Vander Stoep, A., Kearney, A., Smith, N. L., \& Dunbar, M. D. (2011). Validation of the normalized difference vegetation index as a measure of neighborhood greenness. Annals of Epidemiology, 21(12), 946-952.

Rouse, J. W., Haas, R. H., Schell, J. A., \& Deering, D. W. (1974). Monitoring vegetation systems in the Great Plains with ERTS. NASA Special Publication, 351, 309.

Sentera, 2021. Sentera sensör üreticisi (Double 4K Multispektral Tarım Sensör), ABD. https://sentera.com/introducing-multispectral-double-4k-sensor/ Erişim tarihi: 02 Şubat 2021.

Taghvaeian, S., Chávez, J. L., \& Hansen, N. C. (2012). Infrared thermometry to estimate crop water stress index and water use of irrigated maize in Northeastern Colorado. Remote Sensing, 4(11), 3619-3637.

Tiryaki, T. (2018). Su Stresinin Yağ Gülü (Rosa Damascena Mill.) Fidanlarında Morfolojik Ve Biyokimyasal Özellikler Üzerine Etkisi (Yüksek Lisans Tezi). Süleyman Demirel Üniversitesi Fen Bilimleri Enstitüsü, 78, Isparta.

Tucker, C. J. (1979). Red and photographic infrared linear combinations for monitoring vegetation. Remote Sensing of Environment, 8(2), 127-150.

Uçar, Y. (2011). Performance assessment irrigation schemes according to comparative indicators: A case study of Isparta, Turkey. European Journal of Scientific Research 52(1), 82-90.

Uçar, Y., Kazaz, S., İnal, F. E., \& Baydar, H. (2017). Empirical Models Likely to Be Used to Estimate the Evapotranspiration of Oil Rose (Rosa damascena Mill.). Ziraat Fakültesi Dergisi 12(1), 110.

Wahab, I., Hall, O., \& Jirström, M. (2018). Remote sensing of yields: Application of UAV imageryderived NDVI for estimating maize vigor ve yields in complex farming systems in sub-saharan Africa. Drones 2(3), 28.

Xue, J., \& Su, B. (2017). Significant remote sensing vegetation indices: A review of developments and applications. Journal of Sensors, 17.

Zhang, L., Zhang, H., Niu, Y., \& Han, W. (2019). Mapping maize water stress based on UAV multispectral remote sensing. Remote Sensing, 11(6), 605.

Zhang, L., Han, W., Niu, Y., Chávez, J. L., Shao, G., \& Zhang, H. (2021). Evaluating the sensitivity of water stressed maize chlorophyll and structure based on UAV derived vegetation indices. Computers and Electronics in Agriculture, 185, 106174.

Zhao, C. (2014). Advances of research and application in remote sensing for agriculture. Nongye Jixie Xuebao = Transactions of the Chinese Society for Agricultural Machinery, 45(12), 277-293. 